\title{
ODISEA, XV 160-165: HELENA INTÉRPRETE DE PRESAGIOS
}

HELENA GUZMÁN

UNED. Madrid

hguzman@flog.uned.es

\section{RESUMEN}

Helena en la Odisea presenta algunos rasgos que no aparecen en el resto de la tradición. Concretamente, en XV 160-178 hace gala de la capacidad de interpretar presagios enviados por los dioses en paralelo a los adivinos varones bien conocidos. Es un testimonio más de su peculiaridad como mujer, que se diferencia del tipo convencional femenino en el oíkos, y como esposa en relación con Menelao su marido.

Palabras Clave: Helena de Troya, Odisea, Mitología Clásica.

\section{ABstract}

In the Odyssey, Helen of Troy presents some features that do not appear in later traditions. Specifically, in XV 160-170 she displays her capacity to interpret omens sent by the gods in an analogous way as the well-known male fortune-tellers. It is another testimony of her peculiarity as woman who differs from the conventional feminine archetype in the oikos, and of her singularity as a wife in relation with her husband, Menelaus.

KEY Words: Helen of Troy, Odyssey, Classical Mythology. 
1. La Odisea es primordialmente, claro está, el poema de Odiseo, la narración de las aventuras que este héroe se vio obligado a correr a su regreso de la Guerra de Troya, o sea, su nóstos en el sentido literario del término dentro de la tradición épica griega arcaica. Así las cosas, lo lógico sería que todo el relato estuviera en relación directa y estrecha con su protagonista. Pero el poeta compuso una obra mucho más compleja y moderna de lo esperado. Decidió, con excelente criterio, buscar una más rica diversidad de temas centrales, de forma que el poema quedó organizado en tres grandes bloques: su puente de unión con la Guerra de Troya - lo que de paso se convertía en un enlace con la Ilíada-, sus peripecias por el Mediterráneo y su llegada a Ítaca.

Esa parte de transición mencionada es lo que llamamos la Telemaquia, la búsqueda que emprende Telémaco tras la pista de su padre ya en exceso ausente. Y en ese peregrinaje arriba a Pilos, donde Néstor apenas puede ayudarle en su desasosiego, pero le remite curiosamente al epicentro de la explosión que había desencadenado precisamente la funesta guerra, a Esparta, al lado de Menelao y Helena, que ahora paradójicamente es un remanso de apacibilidad frente a las situaciones de tensión que han encontrado otros héroes a su regreso. De esta forma, Esparta-Menelao-Helena se convierten en el centro de esta primera parte del poema, mientras que Odiseo todavía no ha aparecido personalmente en escena, y sólo tenemos vagas noticias de su hipotético paradero. Ahora bien, con la irrupción de Menelao y Helena en la marcha del relato la presencia de Odiseo se hace de repente más real, puesto que las noticias que ahora surgen lo hacen más próximo.

Es claro, pues, que también en la Odisea Helena goza de una relevancia importante, tal vez contra lo esperado. Pensamos que el canto IV es el núcleo de esta primera parte del poema: Telémaco deambula en busca de alguna información importante sobre el final de guerra y sobre el paradero de su padre, y lo encontrará al lado de dos personajes centrales en el conflicto, Menelao y Helena. Más aún: dentro de la marcha general del poema, cuando parece que ya Odiseo ha ocupado el protagonismo real de la narración, de repente el poeta retorna, en el canto $\mathrm{XV}$, al desenlace de la acción iniciada en la Telemaquia, y volvemos a encontrarnos a Telémaco concluyendo su viaje y disponiéndose para el retorno a Ítaca. Pues bien, también en este pequeño episodio-cierre reaparece Helena, y lo hace con un protagonismo nuevamente insospechado. Dentro incluso de la pareja, y como ya ha sucedido en el canto IV, Helena se destaca frente a su marido: por supuesto que Menelao es la fuente central de la información que viene a buscar Telémaco y, por lo tanto, figura principal en el relato general; pero no es menos cierto que Helena, en un momento dado, sabe convertirse en el foco de mayor teatralidad y emoción del pasaje.

2. La crítica con frecuencia descuida el análisis de la Helena odiseica ${ }^{1}$, aunque hay algunos estudios en los últimos decenios del siglo pasado que dedican cierta atención a esta etapa del relato mítico de la heroína. Stanford² afirma que Helena es «repentant, in-

${ }^{1}$ P.e., entre los grandes manuales, unos ni lo mencionan (RUIZ DE ElviRA [1975]; GANTZ [1993]), y alguno simplemente narra el episodio sin más comentario (ROBERT [1926: 1407]). Entre las monografías suele limitarse el análisis a los pasajes del canto IV, p.e., KAKRIDIS (1971: 40-53), SUZUKI (1989: 57-91), al igual que BETTINI - BRILLANTE (2008: 83-88).

2 STANFORD (1965: comentario a IV 121). 
dustrious, hospitable, domesticated, and still beautiful», adjetivos oportunos, pero evidentes. Clader ${ }^{3}$ piensa que el poeta de la Odisea utiliza a Helena para crear un contraste con Penélope, y ve un constante empeño del poeta por destacar en ella un componente exótico, que pone en relación con Egipto. Austin ${ }^{4}$ pone sobre todo el énfasis en destacar que la naturaleza divina de Helena es más explícita aquí que en la Ilíada.

Es bien sabido que este poema supone un nuevo contexto literario, en el que se funden una diversidad de temas frente al tono monolítico de la Ilíada. Ahora lo mágico, lo maravilloso, lo novelesco se funden con el mundo de la realidad, que es el sufrimiento del héroe en su viaje y el coraje en el momento de la venganza frente a los pretendientes. El resultado de esta fusión de elementos es un relato lógicamente más rico. Y esta característica se manifiesta en el terreno del universo femenino del poema. Las mujeres en la Odisea tienen una presencia mucho más activa, y variada, que en la Ilíada. Prescindiendo lógicamente de Penélope, que, aunque físicamente ausente en buena parte del poema, se la siente siempre presente en cada episodio del héroe, las demás mujeres de alguna manera se reparten el resto del poema. Circe y Calipso - de alguna forma también las Sirenas - son las mujeres que ocupan el lado mágico y maravilloso de la etapa viajera. Frente a ellas Arete, la mujer de Alcínoo, representa el prototipo femenino convencional dentro de ese mismo período narrativo. Helena es el personaje femenino que se yergue de forma destacada en la Telemaquia.

3. En la Ilíada Helena presenta un esquema ambiguo, en alguna medida anticipador de los planteamientos de la Tragedia: su existencia transcurre en medio de la tensión entre extremos contrarios. Pero en la Odisea la realidad es muy distinta. Ahora nos atreveríamos a sugerir que tenemos delante a una Helena compleja, en la que se funden elementos diversos pero no contrapuestos, lo que elimina el dramatismo emocional de la Ilíada. Ahora nuestra heroína representa la función de mujer tradicional dentro del oíkos, pero al tiempo afloran en ella una y otra vez rasgos anómalos dentro de ese esquema-tipo: Helena no es la esposa convencional de un rey de un reino griego, como puede serlo Penélope o Arete. Helena es eso y más. Pero esos nuevos rasgos no la hacen agónica, sino simplemente más activa y, sobre todo, distinta. Los elementos contrapuestos de la Helena iliádica han desaparecido en buena medida, y por ese motivo ahora la contemplamos relajada. Es la segunda etapa del relato mítico de nuestra heroína, la que la conducirá directamente al Campo Elisio. Ahora la encontramos sólidamente asentada, y en paz conyugal, en la misma Esparta de la que tiempo atrás había huido, seducida por Paris y tras abandonar a Menelao, un marido que ahora la mantiene a su lado como si un tupido velo de olvido cubriese un pasado del que todos han perdido el recuerdo.

4. En la Odisea nos encontramos con una Helena absolutamente anómala dentro de la evolución tradicional de su relato. La tradición posterior volverá a los planteamientos de la Helena iliádica, a su conflicto central: el abandono de su marido. Pero en este otro poema aparecen algunos rasgos específicos, que no volverán a reaparecer y que confi-

3 Clader (1976: 24-40).

4 Austin (1994: 71-89). 
guran un perfil de mujer sabia, conocedora de saberes mágicos o, en cualquier caso, no característicos de su función de mujer-esposa dentro del oíkos.

En trabajos anteriores ${ }^{5}$ he comentado su intervención como maga y como contadora de historias. Ahora analizaré un pasaje del canto XV donde se nos revela como intérprete de presagios.

El poeta, tras narrar la llegada de Odiseo a Ítaca a partir del canto XIII, retoma la figura de Telémaco, que ha sido el protagonista de la narración durante los cuatro primeros cantos en busca de noticias sobre su padre. El poeta planea hacerle llegar también a Ítaca, y en el canto XV dispone la acción a tal efecto: Atena se acerca al joven héroe y le insta a regresar a su patria; él se pone en movimiento y dispone la despedida de sus anfitriones Menelao y Helena, que le prestan las atenciones últimas con la entrega de sendos regalos. Ya subido al caballo, y cuando está punto de partir, en ese preciso momento ocurre un suceso que al punto es tenido como un prodigio ( $\tau \dot{\varepsilon}$ pas) enviado por los dioses y que, desde el primer momento, es interpretado como positivo dado el giro hacia la derecha que toma el vuelo (XV 160-165):

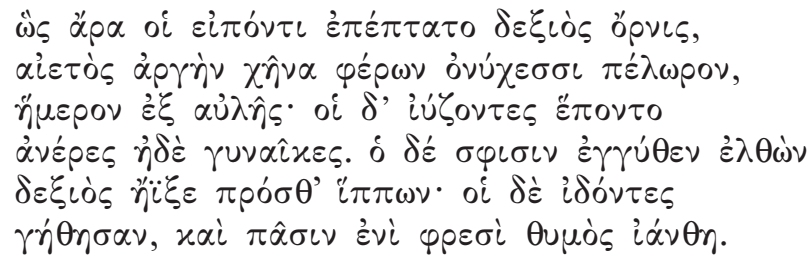

Mientras le decía esto voló a su derecha un ave, un águila que llevaba en sus garras una oca blanca, grande, doméstica, de algún corral. La perseguían chillando hombres y mujeres, y al llegar cerca de ellos torció hacia la derecha por delante de los caballos. Al verlo se alegraron ellos, y a todos se les llenó el ánimo de contento.

Los presentes buscan al punto una explicación ${ }^{6}$, y es importante analizar la reacción de Menelao y Helena al respecto. Él se detiene a reflexionar sobre lo sucedido, antes de emitir un juicio (169-170):

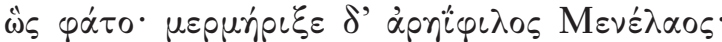

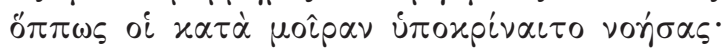

Así dijo. Y Menelao, grato a Ares, meditó dubitativo: qué pensar y cómo le respondería con un juicio atinado.

La intensa utilización de términos que indican «reflexión» en este corto espacio de dos hexámetros, indica ya claramente la intención del poeta de presentar a un Menelao

\footnotetext{
5 Cf. GuZMÁn (2005) y GuZMÁn (2006).

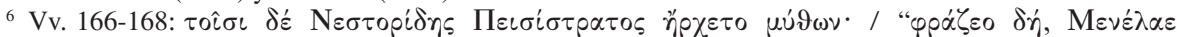

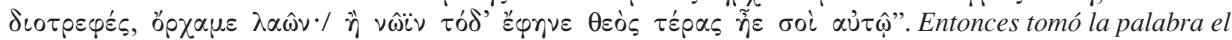
hijo de Néstor, Pisístrato: "Explícanos, Menelao, de estirpe divina, señor de guerreros, si para nosotros o para ti un dios nos envió este prodigio».
} 


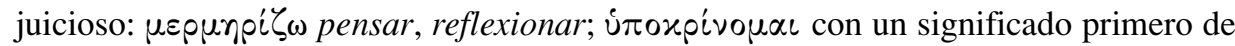

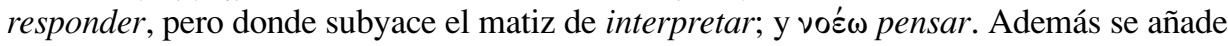
la expresión $\chi \alpha \tau \dot{\alpha} \mu o \hat{\imath} \rho \alpha \nu$, en la que el término $\mu o \hat{\imath} \rho \alpha$ significa lo que es correcto, parte o porción adecuada, locución ésa de uso frecuentemente en la Odisea, casi siempre con verbos de decir ${ }^{7}$.

Frente a esta actitud reposada y cauta de Menelao su esposa vuelve a darnos una demostración de su naturaleza psicológica activa, a veces incluso agresiva, en la que su audacia, ya vista en varias ocasiones ${ }^{8}$, la lleva a adelantarse (ن $\left.\tau \circ \varphi \theta \alpha \dot{\alpha} \nu \omega\right)$ a las más lentas deliberaciones de su marido, lo que, de otro lado, no encaja en su rol de mujer entregada a las tareas domésticas. Una vez más Helena es otra cosa. Y en esta ocasión se siente con fuerzas para ejercer incluso la función de adivino (XV 171-173):

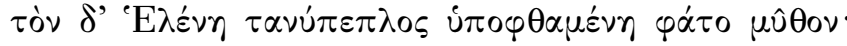

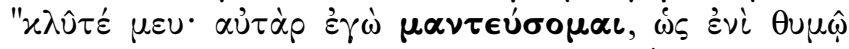

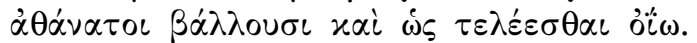

Pero se le anticipó y habló Helena, de amplio peplo: "iEscuchadme! Yo por mi parte voy a dar un vaticinio, tal cual en mi ánimo lo inspiran los inmortales y como creo que ha de cumplirse.

Estos dos versos precisan de un análisis detenido, que nos proporcione una comprensión exacta del sentido último del pasaje.

Primero, Helena utiliza el término $\mu \alpha \nu \tau \varepsilon u ́ o \mu \alpha \iota$, lo que la convierte en una adivina capaz de descifrar los augurios, a primera vista en este caso por el vuelo de las aves como nos precisa el contexto, pero es necesario profundizar más en el sentido general del texto. En casi todos los pasajes en que se utiliza este término, se trata de adivinos profesionales, conscientes de su arte $^{9}$. Sin embargo, hay uno en el que encontramos una expresión

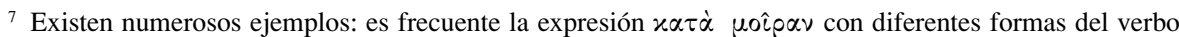
$\lambda \hat{\varepsilon}^{\prime} \gamma \omega$, en su forma simple (II 251, IV 266, VII 227, VIII 141, 397, XIII 48, 385, XVIII 170, XX 37, XXI 278, XXII 486) o compuesta $\varkappa \alpha \tau \alpha \lambda \varepsilon^{\prime} \gamma \omega$ (III 331, VIII 496, X 16, XII 35); también con el mismo significado de decir

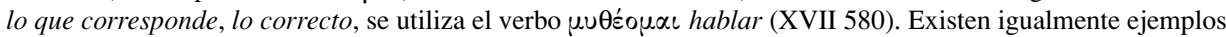
de esta expresión sin verbos de decir pero con el mismo significado de lo que corresponde, en muchos casos con el término $\pi \dot{\alpha} \nu \tau \alpha$ precediendo con el sentido de todo según lo que corresponde: $\pi \dot{\alpha} \nu \tau \alpha$ $\alpha \alpha \tau \dot{\alpha} \mu o \hat{\imath} \rho \alpha \nu$ (III 457, VIII 54, IX 245, 309, 342).

${ }^{8}$ Dejando a un lado sus intervenciones agresivas en la Ilíada, en el canto IV de este otro poema vemos cómo se adelanta también a Menelao a la hora de identificar a Telémaco, aunque su marido ya lo había intuido, dado su parecido con Odiseo (IV 138 ss.).

${ }^{9}$ Haliterses Mastórida, un experto en el conocimiento de los pájaros y en la explicación de los presagios

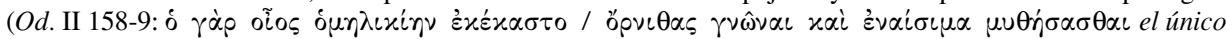
de su generación que se había destacado en distinguir los vuelos de las aves y en revelar sus augurios), habla a los habitantes de Ítaca y les dice que se está cumpliendo todo cuanto le vaticinó a Odiseo antes de su marcha (II

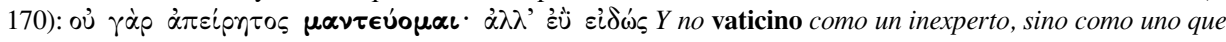
sabe bien.

En Od. IX 507-512 el Cíclope reconoce a Odiseo que un experto adivino, Télemo Eurímida, ya le había va-

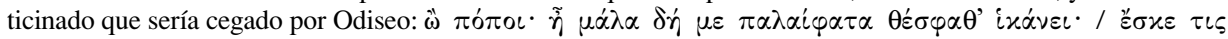

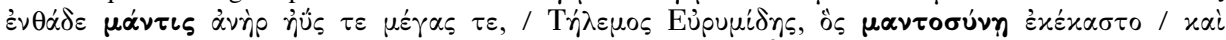

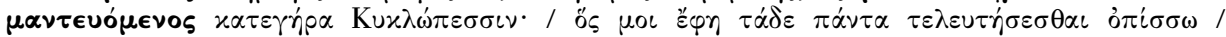

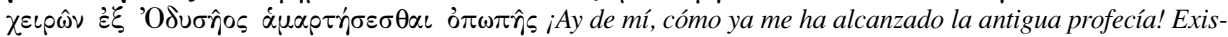


paralela, formular, a la aquí analizada de Helena: en I 200-202 Atena, disfrazada de Mentes, se presenta a Telémaco y quiere vaticinarle, aunque reconoce que no es adivino, que Odiseo ya no estará lejos de casa por mucho tiempo:

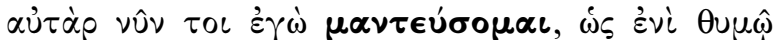

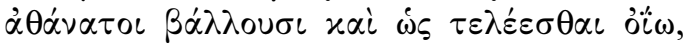

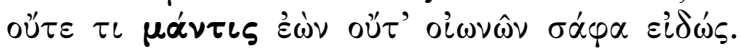

Yo por mi parte ahora voy a darte un vaticinio, tal cual en mi ánimo lo inspiran los inmortales y como creo que ha de cumplirse, y no porque yo sea adivino de oficio ni un experto en augurios.

5. Bouché-Leclerq ${ }^{10}$ habla de dos tipos generales de adivinación: la inductiva o externa, en la que la información se obtiene de elementos externos y para cuyo dominio sólo es preciso conocer las reglas que rigen esos comportamientos externos. Y luego está la intuitiva o interior, que exige algún tipo de comunicación con la divinidad. Esta última puede ser «entusiástica», cuando el adivino es un mero intermediario mecánico en la transmisión adivinatoria, o bien puede suceder que éste proceda a una reelaboración e interpretación del mensaje recibido de los dioses. Es evidente que en nuestro caso estamos ante el último tipo: Helena se siente inspirada por la divinidad, pero además somete esa sensación a su propia consideración. No es un ornitomante profesional ni tampoco una variante de la posterior pitonisa délfica. Supone una realidad intermedia: es alguien que se siente inspirada pero que luego es sabedora de las normas que regulan esa intuición

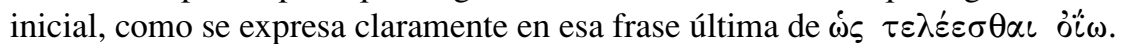

De otro lado, hay un elemento que suele pasar por alto a los comentaristas, pero que enlaza una vez más a Helena con la maga Circe y la ninfa Calipso. La función última de esta escena adivinatoria es un «anuncio de futuro» para Telémaco, que está buscando con desesperación a su padre. Pues bien, en las escenas de despedida correspondientes a esos dos personajes femeninos vemos que igualmente una y otra adelantan el futuro a Odiseo, cuando también está para partir.

tió aquí un cierto adivino, valiente y notable, Télemo Eurímida, que fue afamado por su saber vaticinador, y ejerciendo su arte de vaticinio envejeció entre los cíclopes, quien me dijo todo cuanto iba luego a realizarse: que perdería mi vista a manos de Odiseo.

En $O d$. XV 252-255 se alude a Polifides, al que el propio Apolo había concedido el don del vaticinio: $\alpha u ̉ \tau \grave{\rho}$

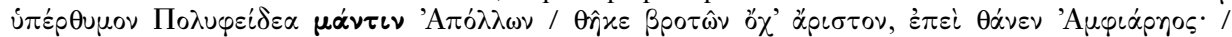

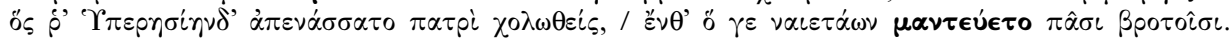
$Y$ al magnánimo Polifides Apolo lo hizo adivino, el mejor con mucho de los mortales una vez que hubo muerto Anfiarao. Éste se retiró a Hiperesia encolerizado contra su padre y, habitando allí, daba sus vaticinios a todos los mortales.

Teoclímeno aparece tres veces en este poema (Od. XV 525-538, XVII 151-161 y XX 350ss.), y en XVII 154

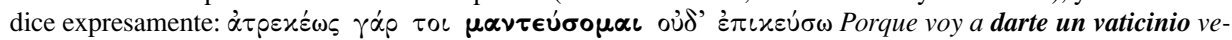
raz y sin ambages.

Finalmente, también hay una mención de Tiresias, el adivino por excelencia. En Od. XXIII 251 el héroe se

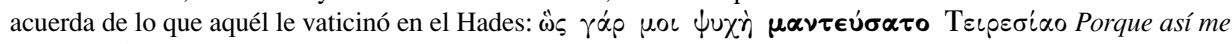
lo vaticinó el alma de Tiresias.

10 BouChÉ-LeCLERCQ (2003: 96). 
6. Finalmente viene la interpretación mántica de nuestra heroína (174-178).

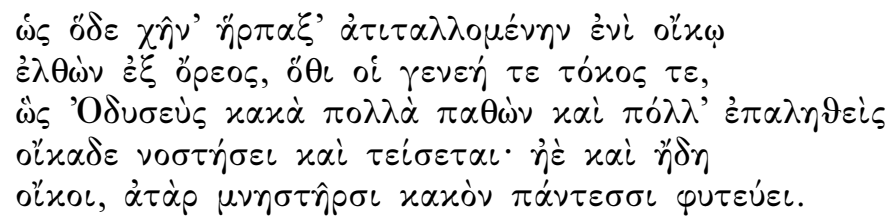

Como el águila arrebató una oca criada en la casa, llegando desde el monte, donde tiene su guarida y sus crías, así Odiseo, después de sufrir muchos males y vagar largo tiempo, volverá a su hogar y cumplirá su venganza. O acaso ya está en su tierra y maquina el castigo de todos los pretendientes.

La predicción propiamente dicha del prodigio, aunque va a resultar real y, por lo tanto, el valor de Helena como adivina va a quedar fuera de toda duda, es un tanto absurda. Si tenemos en cuenta que el águila que captura a la oca es el elemento negativo, dado que la oca estaba tan contenta comiendo entre los suyos, no tiene sentido su comparación con Odiseo, porque en ese caso sería un paralelismo poco afortunado ${ }^{11}$.

\section{BIBLIOGRAFÍA}

Austin, N., (1994), Helen of Troy and her shameless phantom, Cornell Univ. Press.

Bettini, M. - Brillante, C. (2008) El mito de Helena. Imágenes y relatos de Grecia a nuestros días, Madrid, (ed. orig. ital., 2002).

Bouche-LeclercQ, A. (2003), Histoire de la divination dans l'Antiquité, Grenoble (ed. orig. fr., 1879-1882)

Clader, L. L. (1976), Helen. The evolution from divine to heroic in Greek epic tradition, Leiden.

GANTZ, T., (1993), Early Greek Myth. A guide to literary and artistic sources, Baltimore.

GuZmán, H (2005), «Helena la maga (Odisea IV 219-233)», en: J. Costas RodríGuEZ (ed.), Ad amicam amicissime scripta. Homenaje a la Prof. María José López de Ayala y Genovés, Madrid, UNED, 69-76.

Guzmán, H. (2006), «Helena contadora de historias (Odisea IV 233-264)», en: E. CALderón Dorda - A. Morales Ortiz - M. Valverde Sánchez (eds.), Koinòs lógos. Homenaje al Prof. José García López, Universidad de Murcia, pp. 405-412.

KAKRIDIS, J. Th., Homer revisited, Lund.

RoBert, C., (1926), Die griechische Heldensage, en Preller, L., Griechische Mythologie, II, 4. ${ }^{a}$ ed., Berlín.

11 A decir verdad, el mismo defecto tiene la interpretación que el propio Odiseo da del sueño de Penélope en XIX 535-558. Penélope cuenta a Odiseo un sueño para que se lo interprete (usa el verbo ú mo que se había usado para indicar cómo Menelao pensaba en dar una explicación al presagio): había veinte ocas comiendo alegremente en el palacio de Penélope y ella se alegraba al verlos, pero desde el monte bajó un águila y los mató; mientras la reina se lamentaba profundamente llorando a gritos por la muerte de las ocas, el águila volvió, se posó en el palacio y con voz humana le dijo que lo que había visto no era un sueño sino un hecho real en el que las ocas eran los pretendientes y el águila era el propio Odiseo, que había regresado para dar a los pretendientes un destino vergonzoso. Cuando Penélope despertó, las ocas estaban en el palacio picoteando el trigo, como de costumbre. 
RuIz De Elvira, A., (1975), Mitología clásica, Madrid.

STANFORD, W. B. (1965), Homer. Odyssey, Londres, $2 .^{a}$ ed.

Suzuki, M. (1989), Metamorphoses of Helen. Authority, difference, and the Epic, Cornell Univ. Press. 